\title{
A critical review and recommendations over product designing problems faced by new product designers in agriculture
}

Ekta Melkani, Manju Mehta and Kiran Singh

See end of the paper for authors' affiliations Ekta Melkani

Department of Family Resource Management, C.C.S. Haryana Agricultural University, Hisar (Haryana) India

Email : ektamelkani@gmail.com
Received: 07.03.2020; Accepted: 21.05.2020

DABSTRACT : Designers of Agricultural products have major playing roles to keep trying to uplift the agricultural sector dignity by producing innovative design insights. Product designers work alongside engineers and model makers to conduct research and device an accurate design proposal for projects. Agricultural excellence could be attained through technological advancement and innovation in design. The major implications of an innovative product development postures for the agricultural research organization and management along with the role of design function in innovation development. The appropriate agricultural technologies harmonize with the environment, maximize and minimize its benefit and harmful effects, respectively while requiring an intelligent balance of labour-intensive and capital-intensive parts of technologies. The intensive innovation activity nowadays in agricultural sector is becoming an essential part of development and considered as a major factor in the contribution to the production development and efficiency in the market economy. The shaping and advancing strategy of the innovation system is aimed at assimilating the novelties making it possible to launch new production technological structure and to ensure competitiveness of enterprises both domestically and internationally in markets. New product development in agricultural risk management using integrated approach should be made to crop insurance improvement so that farmers are drawn to adopt innovative technologies and designers are motivated to design new for no loss of uncertainties of future marketing.

KEY WORDS: Agriculture product designers, Designing issues, Design innovation

- HOW TO CITE THIS PAPER : Melkani, Ekta, Mehta, Manju and Singh, Kiran (2020). A critical review and recommendations over product designing problems faced by new product designers in agriculture. Asian J. Home Sci., 15 (1) : 155-160, DOI: 10.15740/HAS/AJHS/15.1/155-160. Copyright@ 2020: Hind AgriHorticultural Society. 